\title{
Cytomegalovirus and Herpes Simplex Infections in Mothers and Newborns in a Havana Maternity Hospital
}

\author{
Aimée Festary MD MS, Vivian Kourí MD MS PhD, Consuelo B. Correa MD MS PhD, Denis Verdasquera MD MS PhD, \\ Tania Roig MD MS PhD, Martha P. Couret MD MS
}

\begin{abstract}
INTRODUCTION Cytomegalovirus and herpes simplex virus are associated with congenital or perinatal infection, causing potential damage to the newborn.

OBJECTIVES Determine the prevalence of active or latent infection by cytomegalovirus and herpes simplex virus in a population of mothers, congenital infection by these agents in their infants, and association between prevalence of virus infection in mothers and in their newborns.

METHODS A cross-sectional study was conducted from June to September 2012 in a population of 95 pregnant women admitted to the $\mathrm{Dr}$ Ramón González Coro University Maternity Hospital during the third trimester of pregnancy, and their infants (98). Patients were tested for antibodies specific to these viruses; vaginal swabs and urine from the women and serum and urine from the newborns were tested for viral
\end{abstract}

\section{INTRODUCTION}

Herpesviruses are a group of viruses that may have serious implications for infant morbidity and mortality. One of these, cytomegalovirus (CMV), can cause serious birth defects when acquired or reactivated during pregnancy, especially if infection occurs in the first 20 weeks. Another, herpes simplex virus (HSV), can be associated with congenital or, more often, perinatal infection, potentially damaging the newborn.[1,2]

Seroepidemiological studies have shown that both viruses are widespread in human populations globally. Prevalence is higher and the virus is acquired at an early age among people of low socioeconomic status, in whom CMV prevalence can be as high as $100 \%$.[1] Globally, HSV seroprevalence in adults is estimated at $60 \%$ for HSV-1 and $20 \%$ for HSV-2.[2] Incidence of congenital CMV infection is $0.5 \%-2.2 \%$ in developed countries, higher in developing countries;[1] in the USA, it is the leading cause of congenital anomalies. Neonatal herpes is a serious systemic disease with high morbidity and mortality and variable incidence (1.6-20/100,000 births); most infections are acquired in the birth canal from infected maternal secretions.[3]

Serological techniques are useful for determining in an immunocompetent host whether an infection occurred in the past (indicated by $\operatorname{lgG}$ ) or recently (indicated by IgM or by IgG seroconversion). IgM may be present in both primary and recurrent infections, but also may be absent during primary infection.[1-3] Therefore, CMV IgG seroconversion during pregnancy indicates primary infection, while detection of CMV IgG and IgM antibodies indicates active infection, but does not confirm presence of primary infection.[1]

Active infection during pregnancy is the presence of recent viral replication, whether primary or not. It is characterized by the presence of serological markers (IgM or $\lg G$ antibody serocon- genome. The Fisher exact test with $95 \%$ confidence interval was used for comparisons.

RESULTS Of the women studied, $89.5 \%$ tested positive for cytomegalovirus and $83.2 \%$ for herpes simplex. Active infection from cytomegalovirus was detected in $16.7 \%$, and from herpes simplex in $3.2 \%$. Congenital cytomegalovirus infection was detected in $4.1 \%$ of newborns; no herpes simplex virus infection was found in this group. Two newborns of women with active cytomegalovirus infection were congenitally infected.

CONCLUSIONS Serology demonstrated that most of the women were immune to both viruses. Active cytomegalovirus infections are common in this population, and newborns of women with active cytomegalovirus infection during pregnancy are at increased risk of congenital infection.

KEYWORDS Congenital infection, perinatal infection, cytomegalovirus, herpes simplex virus, pregnant women, newborns, Cuba

version), with or without detectable virus in host body fluid. Congenital infection is infection of the fetus or newborn acquired in utero, symptomatic or not. It is characterized by detection of virus in any body fluid or specific $\operatorname{lgM}$ in serum during the first three weeks after birth.[4,5]

Perinatal infection by these agents refers to infection acquired at birth or in the first days of life. Clinical signs of CMV and HSV acquired in the birth canal begin to appear from the tenth day of life. The virus is not detectable during the first three days of life, but later may be found in blood and in some body fluids. However, elevated specific IgM levels are not constant, detectable from 15 days after birth.[4,5]

In Cuba, CMV prevalence in pregnant women and incidence of congenital infection in newborn infants has been the subject of two previous studies. High CMV seroprevalence and intermediate incidence of congenital CMV infection was observed in the later study, conducted in 2007-2008.[4,5] No studies have been carried out concerning HSV seroprevalence or frequency of HSV shedding in pregnant Cuban women, and incidence of congenital or perinatal HSV infection in neonates is unknown.

Identification of a newborn with congenital or perinatal infection with these viruses is necessary for monitoring and early detection of clinical complications in the neonatal period, or hearing, visual, or psychomotor developmental sequelae that may not be detectable at birth but require early intervention. It is essential, therefore, to identify pregnant women at risk of transmitting the infection to their infants during the prenatal or perinatal period. This study seeks to determine prevalence of active or latent CMV and HSV infection in pregnant women in the population studied, as well as prevalence of congenital CMV and HSV infection in infants born to them, and the association between CMV and HSV prevalence in these women and in their neonates. 


\section{METHODS}

A cross-sectional study was conducted. The study population comprised 95 women admitted during the third trimester of pregnancy to Havana's Dr Ramón González Coro University Maternity Hospital (HMURGC) obstetrics service in June to September 2012, who agreed to participate with their newborns (98 infants) and who did not withdraw during the study or followup periods. Reasons for admission to hospital were abnormalities found during pregnancy, chronic diseases (associated with pregnancy or not) or full-term pregnancy.

All participants were interviewed, using a previously prepared questionnaire. Blood and urine samples were collected and a vaginal swab was performed upon admission. In addition, blood and urine samples were collected from all newborns of participating mothers in the first three days of life.

Samples of serum were taken from participating women and their newborns to determine the presence of $\lg G$ and $\operatorname{lgM}$ antibodies to CMV and HSV (commercial ELISA kits DiaSorin, Italy). Multiple nested PCR was used for urine samples and vaginal swabs from the women and for urine and serum samples from the newborns. This PCR allows detection of five viruses of the herpesvirus family (HSV, varicella zoster, CMV, human herpes virus 6, and EpsteinBarr virus) in a single test tube, as described by Tenorio,[6] by amplifying a fragment of the viral polymerase gene of this group of viruses. In addition, a segment of the genome of an internal control (swine pseudorabies) was included to confirm whether or not the amplification reaction occurred in each run.

Both serology and viral genome detection were performed at the sexually-transmitted infections laboratory of the virology department, at Havana's Pedro Kourí Tropical Medicine Institute (IPK). These tests were performed to detect active infection. Medical records were reviewed during hospital stay to identify possible complications associated with herpesvirus infection.

A database was compiled for variable analysis using SPSS 11.5. Prevalence was calculated of active infection (detection of either IgM or viral genome) or latent CMV and HSV infection in mothers and of congenital infection (whether by detection of IgM or viral genome) in newborns. Absolute and relative frequencies were calculated for the remaining variables. The prevalence odds ratio (POR) was calculated with its 95\% confidence interval $(\mathrm{Cl})$ to assess associations between risk factors in mothers (prepregnancy pathology, multiple pregnancy and pregnancy complications) and in newborns (preterm, low birth weight, cesarean section, instrumented delivery and physical signs of possible herpetic infection) and CMV and HSV prevalence (CMV or HSV IgM; HSV- or CMV-positive PCR in blood, urine or vaginal swab; and latent or active CMV and HSV infection). The Fisher exact test was used for comparisons with a significance threshold of $p<0.05$.

Ethics The study adhered to the Declaration of Helsinki and the ethical institutional standards of modern medicine. It was approved by the IPK and HMURGC research ethics committees. Qualified personnel explained the study in plain language to participating women before obtaining their written consent. A copy of the informed consent was provided to each participant. Study procedures ensured confidentiality of all personal data.

\section{RESULTS}

CMV and HSV serology in pregnant women Most of the women were infected before the third trimester of pregnancy by CMV $(89.5 \%)$ and HSV (83.2\%), as evidenced by presence of the respective IgG.

CMV IgM was found in seven women $(7.4 \%)$ in the third trimester and HSV IgM, in two (2.1\%), indicating recent active infection. All women with CMV or HSV IgM also had specific IgG antibodies.

Four women with CMV IgM reported prepregnancy pathology. Abnormalities in the current pregnancy (Table 1) were found in six patients with CMV IgM and two with HSV IgM.
Table 1: Prepregnancy pathology and pregnancy abnormalities associated with active CMV and HSV infection in mothers $(n=95)$

\begin{tabular}{|c|c|c|c|c|c|c|}
\hline Medical history & & $\begin{array}{l}\text { Mothers } \\
\text { n (\%) }\end{array}$ & $\begin{array}{c}\text { CMV IgM+ } \\
(n=7) \\
n(\%)\end{array}$ & $\begin{array}{c}\text { HSV IgM+ } \\
(n=2) \\
n(\%)\end{array}$ & $\begin{array}{c}\text { CMV PCR+ } \\
(n=9) \\
n(\%)\end{array}$ & $\begin{array}{c}\text { HSV PCR+ } \\
(n=1) \\
n(\%)\end{array}$ \\
\hline \multirow{6}{*}{$\begin{array}{l}\text { Prepregnancy } \\
\text { pathology }\end{array}$} & Total $^{a}$ & $49(51.6)$ & $4(57.1)$ & 0 & $4(44.4)$ & $1(100.0)$ \\
\hline & Heart disease & $19(20.0)$ & $1(14.3)$ & 0 & $2(22.2)$ & 0 \\
\hline & Hypertension & $17(17.9)$ & $3(42.9)$ & 0 & 0 & 0 \\
\hline & Bronchial asthma & $8(8.4)$ & 0 & 0 & $1(11.1)$ & 0 \\
\hline & HSV genital lesions & $3(3.2)$ & 0 & 0 & $1(11.1)$ & $1(100.0)$ \\
\hline & Other ${ }^{\mathrm{b}}$ & $7(7.4)$ & $1(14.3)$ & 0 & 0 & 0 \\
\hline \multirow{9}{*}{$\begin{array}{l}\text { Abnormalities in } \\
\text { current pregnancy }\end{array}$} & Total $^{\mathrm{a}}$ & $70(73.7)$ & $6(85.7)$ & $2(100.0)$ & $7(77.8)$ & $1(100.0)$ \\
\hline & Gestational hypertension & $15(15.8)$ & $1(14.3)$ & $1(50.0)$ & $1(11.1)$ & 0 \\
\hline & Suspected low fetal weight & $21(22.1)$ & $2(28.6)$ & $1(50.0)$ & $3(33.3)$ & $1(100.0)$ \\
\hline & Oligoamnios & $10(10.5)$ & $1(14.3)$ & 0 & 0 & 0 \\
\hline & Risk of preterm delivery & $8(8.4)$ & 0 & 0 & $1(11.1)$ & \\
\hline & Threatened preterm delivery & $5(5.3)$ & 0 & 0 & $2(22.2)$ & 0 \\
\hline & Respiratory signs & $7(7.4)$ & 0 & 0 & 0 & 0 \\
\hline & $\begin{array}{l}\text { HSV lesions in skin or } \\
\text { mucous membranes }\end{array}$ & $1(1.1)$ & 0 & 0 & 0 & $1(100.0)$ \\
\hline & Other ${ }^{c}$ & $33(34.7)$ & $3(42.9)$ & 0 & $1(11.1)$ & $1(100.0)$ \\
\hline $\begin{array}{l}\text { No prepregnancy } \\
\text { pathology or } \\
\text { abnormalities in } \\
\text { current pregnancy }\end{array}$ & Total & $5(5.3)$ & 0 & 0 & $1(11.1)$ & \\
\hline
\end{tabular}

a Women could have several prepregnancy pathologies or abnormalities in current pregnancy

b Scleroderma, gastritis, anemia, lupus

c In vitro fertilization, artificial insemination, placenta previa, polyhydramnios, urinary tract infection, arthralgia, myalgia 
Herpesvirus genome detection in mothers CMV was the virus detected most frequently in vaginal swab samples (9 women, 9.5\%); one woman who excreted CMV vaginally also excreted it in urine. None of the women who excreted CMV genetic material had CMV IgM; all had CMV IgG.

Four mothers in whom CMV genetic material was detected had prepregnancy pathologies. Seven of the nine patients PCR-positive for CMV had abnormalities in the current pregnancy; one had both suspected low fetal weight and risk of preterm delivery (Table 1).

Unlike CMV, HSV was not detected in any of the urine and vaginal swab samples in this study. Perianal lesions clinically suspected as herpetic were found in one woman, for whom clinical diagnosis was virologically confirmed. She was one of the patients with a history of genital herpetic lesions and suspected low fetal weight during pregnancy (the result of in vitro fertilization) (Table 1). This patient had HSV IgG on serology.

CMV and HSV serology and virus detection in newborns All children of CMV- and HSV-immune mothers had IgG to the respective viruses, which is expected owing to passive transplacental transfer of IgG. CMV IgM was detected in two infants $(2 \%)$, an indicator of congenital infection, since IgM does not cross the placenta and is self synthesized. One of the mothers of these two children had a history of hypertension and suspected low fetal weight during pregnancy, and was positive for CMV IgM; the child was congenitally infected and had low birth weight. The other mother had oligohydramnios, and, after vaginal delivery, the newborn did not present abnormalities on physical examination.

CMV genome was found in serum of two newborns. The mother of one had a history of genital HSV lesions; a dichorionic, diamniotic twin pregnancy with risk of preterm birth resulted in preterm vaginal delivery of jaundiced twins; one was congenitally infected with CMV, jaundiced because of maternal-fetal blood group incompatibility; the other had physiological jaundice. The mother of the other congenitally infected newborn developed gestational hypertension and urinary tract infection with fever, as well as genital shedding of CMV. Her infant was asymptomatic during the first 72 hours of life.

In summary, four infants $(4.1 \%)$, were congenitally infected with $\mathrm{CMV}$ (two with CMV IgM and two with CMV genome detected in serum). None had HSV IgM or HSV genetic material in serum or urine.
Relationship of active CMV infection in mothers with congenital infection in neonates

In all, 16 women (16.8\%) developed active CMV infection during pregnancy ( 7 had CMV IgM, and CMV genome was detected in 9). Of the four congenitally infected newborns, two were born to mothers with active CMV infection during the last gestational trimester (one woman had CMV IgM; the other, CMV excretion, as indicated in Table 2). Congenital CMV infection, therefore, was three times more common (POR 3.25, Cl 1.09$9.68, p=0.07)$ in infants born to mothers with active infection during pregnancy (Figure 1).

Furthermore, two of the four newborns congenitally infected with CMV showed clinical signs within the first 72 hours of life. One had jaundice due to maternal-fetal blood group incompatibility and another low birth weight; both were born to mothers with prepregnancy pathology. No association was found, however, between the different risk factors and presence of active CMV or HSV in pregnant patients or congenital infection in neonates $(p>0.05)$.

\section{DISCUSSION}

Detection of CMV and HSV antibodies in pregnant women The results found for prevalence of CMV IgG agree with those previously reported by Correa in Cuba, in a study of 1131 pregnant women in three municipalities of Havana, where a prevalence of $92.7 \%$ was found.[5] Similar values are also reported in other

\begin{tabular}{l}
\begin{tabular}{l} 
Table 2: Relationship between mothers' and newborns' virology results $(n=95)$ \\
Maternal results \\
\cline { 3 - 6 }
\end{tabular} \\
\cline { 2 - 6 }
\end{tabular}

Figure 1: CMV and HSV frequency in mothers and their newborns

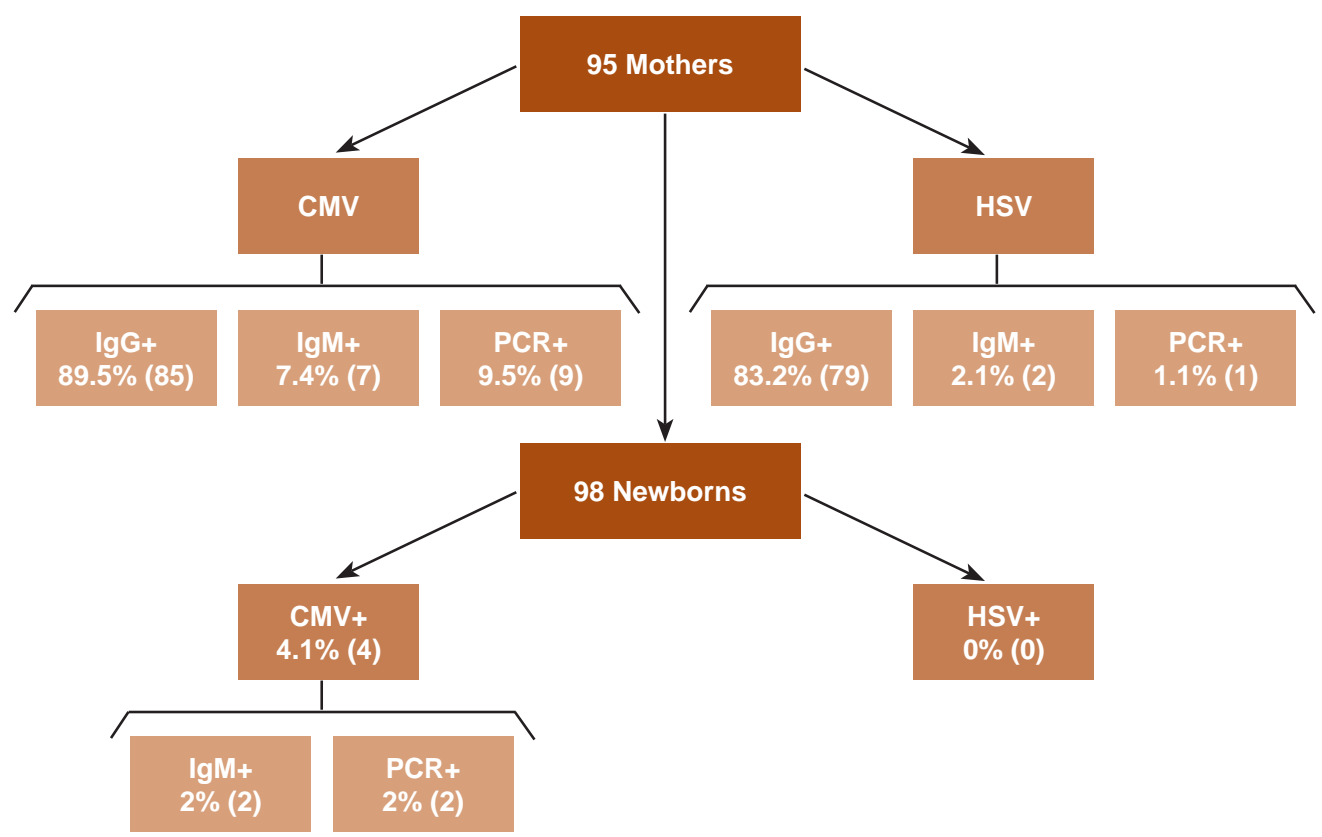


Latin American countries, such as 92.9\% in Colombia in 2008[7] and $84 \%$ in Panama in 2007.[8] Developed countries show lower prevalence of CMV infection in pregnant women, as seen in studies conducted in Portugal (2001-2002, 77\%) and Germany (1996-2010, 42.3\%).[9,10]

Globally, prevalence of HSV antibodies is generally lower than CMV prevalence, especially for HSV type 2, <33\%,[11,12] whereas for HSV-1, values $<65 \%$ are described in the general population.[11,13] In this study, serological screening was performed using a commercial kit that detects antibodies to both viruses (HSV-1 and -2), which may explain the higher percentage of seropositivity than in previous reports.

HSV and CMV incidence increases with age, low socioeconomic status and presence of other sexually transmitted infections. [14] This was not observed in our study, probably because of the small sample size, which precluded demonstration of these associations.

Presence of IgM for either of these viruses indicated active infection during the current pregnancy. We were unable to conduct further studies-including studies of specific IgG antibody avidity, for example - to determine whether these constituted primary infections, and this is one of the main limitations of our research.

The rate we found for CMV IgM in the third trimester of pregnancy $(0.8 \%)$ was higher than that reported by Correa in the first trimester of pregnancy.[5] This may be related to the later timing and to inclusion of a number of patients with prepregnancy pathologies or pregnancy abnormalities requiring hospitalization, conditions that might favor viral reactivation or acquisition of new strains.[15] Findings of a study conducted in Poland, however, showed a high rate of CMV IgM positivity (13\%) in Polish pregnant women with no associated abnormalities.[16]

HSV IgM is rarely found in adults, since most people acquire HSV in childhood, and not all such patients have elevated HSV IgM.[11] In pregnant women, there is a degree of physiological immunosuppression that causes activation of infection by these opportunistic agents. $[11,17]$ If we add the fact that part of the study sample had conditions that increased risk of obstetrical and maternal damage, viral reactivation becomes more likely.

Detection of genome of the studied herpesviruses in samples from pregnant women Asymptomatic CMV excretion in urine and vaginal secretions is a common phenomenon in immunocompetent women of reproductive age. CMV can be isolated in urine and cervical mucus in $2 \%-28 \%$ of pregnant women. Furthermore, it has been demonstrated that during pregnancy, virus excretion increases by $35 \%$, which may account for the high frequency of detection in our study.[17]

Given that asymptomatic HSV excretion can also occur in genital secretions, it can be detected in vaginal swabs and urine samples (owing to the drag mechanism of urine). It is uncommon, however, to find this agent in pregnant women.[18] Genital shedding of these viruses in the third trimester of pregnancy is important in perinatal transmission in the birth canal.[11,17,19] Congenital infection can occur in these cases because of transmission by ascending pathway or, as occurs more often, through blood.[17,20]
Perianal lesions clinically suspected as herpetic were found, however, in one woman, for whom clinical diagnosis was virologically confirmed. Hence, when CMV infection is suspected, a search for viral genetic material should be performed to confirm diagnosis.[21]

A higher frequency of CMV IgM detection (30\%) is normally found in newborns of mothers with poor obstetrical history or abnormalities during pregnancy.[22] Our findings differ from this observation, probably owing to strict antenatal and natal control in Cuba. Kourí found that $1.1 \%$ of Cuban newborns in 2007-2008 were congenitally infected with CMV, through detection of viral genome in saliva and urine samples.[4] The finding of CMV viremia in $2 \%$ of infants in our study is slightly higher, which may be related to the high proportion of our sample with prepregnancy pathologies or abnormalities in the current pregnancy.

CMV and HSV serology and virus genome detection in newborn infants The fact that no infants were found with HSV IgM may be because this virus does not have demonstrated transplacental transmission; hence, congenital HSV infection is rare,[11,23] making it unlikely to find a case of congenital HSV infection in our small sample (only three women with active HSV infection).

The most frequent source of neonatal herpes is perinatal HSV transmission, occurring mainly during passage through the birth canal of mothers excreting HSV in genital discharges, whether or not the women are symptomatic.[24] The facts that HSV IgM synthesis occurs in the first days after acquiring perinatal infection[11] and that this synthesis is delayed in the fetus and the newborn because of immune system immaturity[25] explain why HSV IgM is not detected in newborns. Furthermore, in this study, HSV DNA was only detected in a perianal lesion in one mother, who was prescribed acyclovir and also underwent cesarean section to avoid perinatal virus transmission.

Relationship of active CMV infection in mothers with congenital infection in neonates The relationship between maternal and fetal/neonatal infection has been previously demonstrated. [17] Kourí and Correa reported that Cuban pregnant patients with active CMV infection were at risk of having congenitally infected children when compared with those in whom viral activity was not detected during pregnancy.[4,5]

It is generally understood that pregnant women infected with CMV can transmit this infection during pregnancy, and risk is higher for a mother with primary infection $(5 \%-15 \%)$ than for one with nonprimary infection $(<2 \%)$.[26] This relationship could not be assessed in our study, since we could not differentiate women by type of infection.

According to Lazzarotto, given that CMV is commonly excreted in body secretions during and after pregnancy, its isolation in urine and/or cervical secretions $(57.1 \%$ and $29.2 \%$, respectively) in the first two trimesters of pregnancy is a poor indicator of risk of intrauterine transmission and severity of fetal/neonatal damage.[27]

About $11 \%$ of CMV-infected infants have clinical signs at birth; of these, jaundice is detected in $30 \%$ and intrauterine growth retardation in $47 \%$. Therefore, these findings are common in congenitally infected children.[17] 
Kouri's previous study on congenital CMV infection found that $16.7 \%(2 / 12)$ of congenitally infected infants had clinical signs at birth.[4] As for CMV viremia, our higher findings may be due to the large number of women with prepregnancy pathologies or pregnancy abnormalities that could predispose to higher rates of congenital infection, and to our smaller sample size. Also, the clinical signs associated with congenital infection are not specific to CMV.

It has been demonstrated that CMV transmission rates are lower the earlier the infection occurs in pregnancy, but the proportion of fetuses/neonates with clinical signs among those infected is larger.[17] The two cases of congenital infection from mothers with active maternal infection were probably due to active infection during the first or second trimester.

The present study had the following limitations: small sample size: over-representation of women with pathologies or alterations during pregnancy; and undetermined status of participants prior to third trimester of pregnancy concerning CMV and HSV infections.

This is the first Cuban research to examine active HSV infection in pregnant women and their newborns, as well as the possible relationships among several maternal and neonatal factors.
In addition, the relationship of chronic diseases and pregnancy abnormalities with congenital and perinatal CMV and HSV infection was studied in a group of pregnant women at a specialized hospital. It is important to look for these agents in pregnant women and neonates, since they are becoming more important in developed countries or countries with good health services, where hepatitis B, syphilis and HIV are already diagnosed early. CMV and HSV are not screened for routinely in pregnant women or newborns, but they are currently responsible for most cases of congenital and perinatal infections, with consequent increase in infant morbidity, mortality and longterm sequelae (psychomotor retardation, neurosensory deafness, blindness, etc.). Identifying possible factors associated with CMV and HSV detection in pregnant women and neonates and their early diagnosis during pregnancy or in the neonatal period could therefore help reduce infant morbidity and mortality and prevent sequelae.

\section{CONCLUSIONS}

Most of the Cuban women studied were immune to both CMV and HSV, with active CMV infection more frequent than active HSV infection. Newborns of women with active CMV infection are at greater risk of congenital infection. - $1 /$ -

\section{REFERENCES}

1. Schleiss MR. Congenital cytomegalovirus infection: update on management strategies. Curr Treat Options Neurol. 2008 May;10(3):186-92.

2. Boppana SB, Fowler KB. Persistence in the population: epidemiology and transmission. In: Arvin A, Campadelli-Fiume G, Mocarski E, Moore PS, Roizman B, Whitley R, et al, editors. Human Herpesviruses: Biology, Therapy, and Immunoprophylaxis. Cambridge: Cambridge University Press; 2007.

3. Guías clínicas infecciones TORCH. Protocolo: Infecciones TORCH y por Parvovirus B19 en la gestación [Internet]. Barcelona: Clinic Barcelona Hospital Universitari; 2011 [cited 2012 Nov 23]. 40 p. Available from: http://www.medici nafetalbarcelona.org/clinica/images/protocolos/ patologia_materna_obstetrica/infecciones $\% 20$ torch\%20y\%20pvb19.pdf. Spanish.

4. Kourí V, Correa CB, Verdasquera D, Martínez $\mathrm{PA}$, Álvarez A, Alemán $\mathrm{Y}$, et al. Diagnosis and screening for cytomegalovirus infection in pregnant women in Cuba as prognostic markers of congenital infection in newborns: 2007-2008. Pediatr Infect Dis J. 2010 Dec;29(12):1105-10

5. Correa CB, Kourí V, Verdasquera D, Martínez PA, Álvarez A, Alemán $\mathrm{Y}$, et al. HCMV seroprevalence and associated risk factors in pregnant women, Havana City, 2007 to 2008. Prenat Diagn. 2010 Sep;30(9):888-92.

6. Tenorio A, Echevarría JE, Casas I, Echevarría JM, Tabarés E. Detection and typing of human herpesviruses by multiplex polymerase chain reaction. J Virol Methods. 1993 Oct;44(23):261-9

7. Pordeus V, Barzilai O, Sherer Y, Luiz RR, Blank $\mathrm{M}$, Bizzaro $\mathrm{N}$, et al. A latitudinal gradient study of common anti-infectious agent antibody prevalence in Italy and Colombia. Isr Med Assoc J. 2008 Jan;10(1):65-8.

8. Estripeaut D, Moreno $Y$, Ahumada-Ruiz S, Martínez A, Racine JD, Sáez-Llorens X. [Seroprevalence of cytomegalovirus infection in puerperal women and its impact on their newborns]. An Pediatr (Barc). 2007 Feb;66(2):135-9. Spanish.

9. Lopo S, Vinagre E, Palminha P, Paixao MT, Nogueira P, Freitas MG. Seroprevalence to cyto- megalovirus in the Portuguese population, 20022003. Euro Surveill. 2011 Jun 23;16(25).

10. Enders G, Daiminger A, Lindemann L, Knotek $F$, Bäder U, Exler $S$, et al. Cytomegalovirus (CMV) seroprevalence in pregnant women, bone marrow donors and adolescents in Germany, 1996-2010. Med Microbiol Immunol. 2012 Aug;201(3):303-9.

11. Roizman B, Knipe DM, Whitley RJ. Herpes Simplex Viruses. In: Knipe DM, Howley PM, editors. Fields Virology. Philadelphia: Lippincott Williams \& Wilkins; 2007. p. 2503-601.

12. Tilli M. Review: Infección genital por el virus herpes simple (VHS) durante el embarazo. J Bras Doenças Sex Transm. 2004;16(2):48-52. Spanish.

13. Whitley RJ, Gnann JW. The epidemiology and clinical manifestations of herpes simplex virus infections. In: Roizman B, Whitley RJ, Lopez C editors. The Human Herpesviruses. New York: Raven Press; 1993. p. 69-105.

14. Mertz GJ, Benedetti J, Ashley R, Selke SA, Corey L. Risk factors for the sexual transmission of genital herpes. Ann Intern Med. 1992 Feb 1;116(3):197-202.

15. Saraswathy TS, Az-Ulhusna A, Asshikin RN, Suriani S, Zainah S. Seroprevalence of cytomegalovirus infection in pregnant women and associated role in obstetric complications: a preliminary study. Southeast Asian J Trop Med Public Health. 2011;42(2):320-2.

16. Gaj Z, Rycel M, Wilczyński J, Nowakowska D. [Seroprevalence of cytomegalovirus infection in the population of Polish pregnant women]. Ginekol Pol. 2012 May;83(5):337-41. Polish.

17. Mocarski ES, Shenk T, Pass R. Cytomegaloviruses. In: Howley PM, Knipe DM, editors. Fields Virology. 5th ed. Philadelphia: Lippincott Williams and Wilkins; 2007. p. 2702-57.

18. Choi SJ, Park SD, Jang IH, Uh Y, Lee A. The prevalence of vaginal microorganisms in pregnant women with preterm labor and preterm birth. Ann Lab Med. 2012 May;32(3):194-200.

19. Enders G, Daiminger A, Bäder U, Exler S, Enders $M$. Intrauterine transmission and clinical outcome of 248 pregnancies with primary cytomegalovirus infection in relation to gestational age. $\mathrm{J}$ Clin Virol. 2011;52(3):244-6.
20. Scott GM, Chow SS, Craig ME, Pang CN, Hall $B$, Wilkins MR, et al. Cytomegalovirus infection during pregnancy with maternofetal transmission induces a proinflammatory cytokine bias in placenta and amniotic fluid. J Infect Dis. $2012 \mathrm{Apr}$ 15;205(8):1305-10.

21. Kirimi E, Peker E, Tuncer O, Ozkan M, Ozmen B, Ceylan A. DNA-positive, IgM-negative symptomatic congenital cytomegalovirus infection: two case reports. J Matern Fetal Neonatal Med. 2010 Jul;23(7):725-7.

22. Kishore J, Misra R, Paisal A, Pradeep Y. Adverse reproductive outcome induced by Parvovirus B19 and TORCH infections in women with highrisk pregnancy. J Infect Dev Ctries. 2011 Dec 13;5(12):868-73.

23. Sauerbrei A, Wutzler P. Herpes simplex and varicella-zoster virus infections during pregnancy: current concepts of prevention, diagnosis and therapy. Part 1: herpes simplex virus infections. Med Microbiol Immunol. 2007 Jun;196(2):89-94.

24. Jones CA. Vertical transmission of genital herpes: prevention and treatment options. Drugs. 2009;69(4):421-34.

25. Hayward AR. The human fetus and newborn: development of the immune response. Birth Defects Orig Artic Ser. 1983;19(3):289-94.

26. Ornoy A. Fetal effects of primary and non-primary cytomegalovirus infection in pregnancy: are we close to prevention? Isr Med Assoc J. 2007 May;9(5):398-401.

27. Lazzarotto T, Guerra B, Lanari M, Gabrielli L, Landini MP. New advances in the diagnosis of congenital cytomegalovirus infection. J Clin Virol. 2008 Mar;41(3):192-7.

\section{THE AUTHORS}

Aimée Festary Casanovas, obstetrician-gynecologist with master's degrees in infectious diseases and in maternal/child health. Head of postpartum care, Dr Ramón González Coro University Maternity Hospital (HMURGC), Havana, Cuba.

Vivian Kourí Cardellá, medical microbiologist with master's degree in virology and doctorate 
in medical sciences. Head, sexually transmitted diseases laboratory, virology department, Pedro Kourí Tropical Medicine Institute (IPK), Havana, Cuba.

Consuelo B. Correa Sierra (Corresponding author: consuelocorrea@infomed.sld.cu), family physician and microbiologist with master's degree in virology and doctorate in medical sciences. Researcher, sexually transmitted diseases laboratory, virology department, IPK, Havana, Cuba.
Denis Verdasquera Corcho, family physician with a master's degree in epidemiology and doctorate in medical sciences, epidemiology department, IPK, Havana, Cuba.

Tania Roig Álvarez, neonatologist with master's degree in infectious diseases and doctorate in medical sciences, neonatology department, HMURGC, Havana, Cuba.

Martha P. Couret Cabrera, obstetriciangynecologist with master's degree in maternal/ child health, obstetrics department, HMURGC, Havana, Cuba.

Submitted: February 28, 2014

Approved for publication: January 1, 2015

Disclosures: None

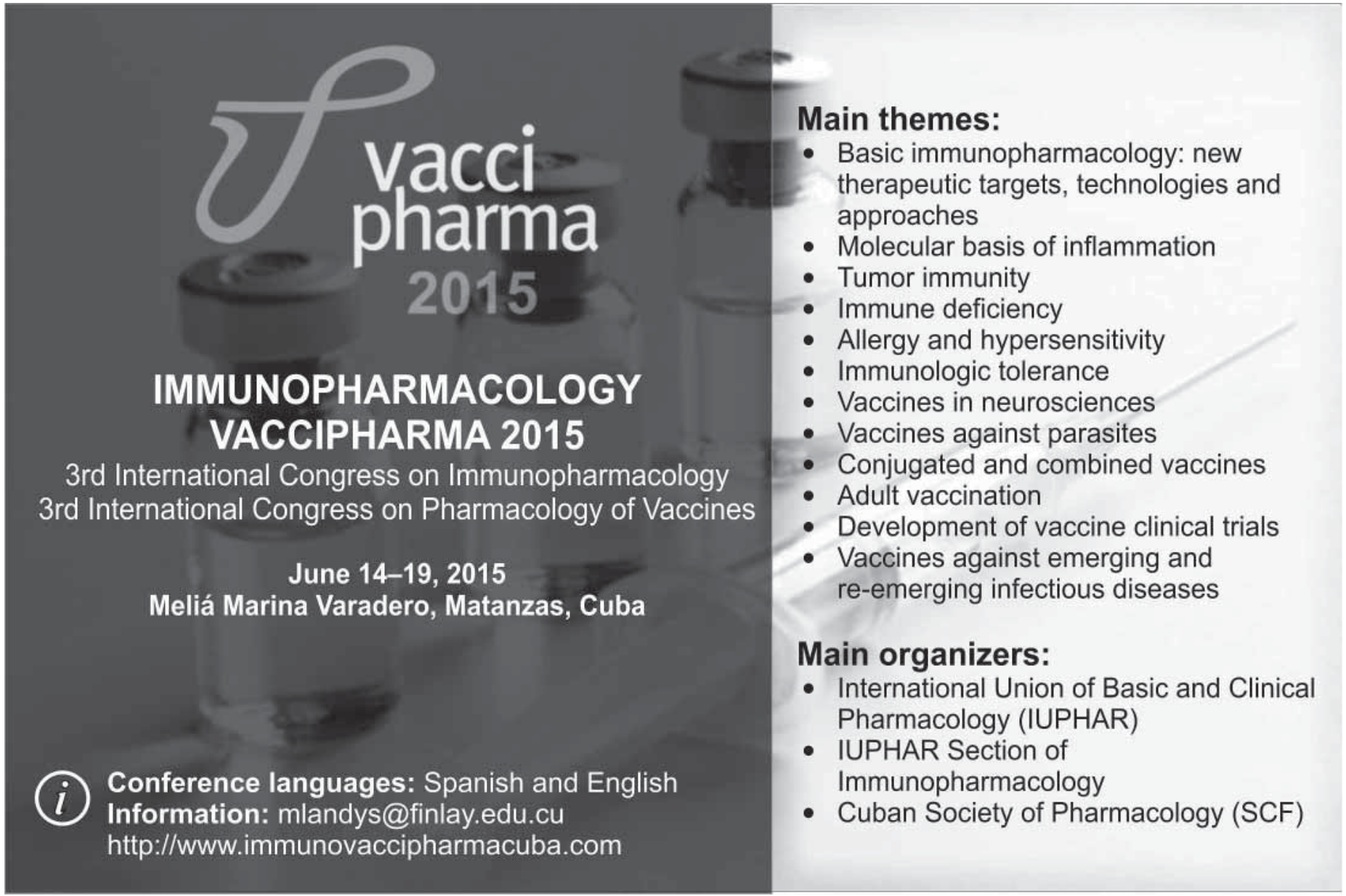

